\title{
THE COMPARISON OF METHODS FOR THE ANALYSIS OF THE CHEMICAL COMPOSITION OF ALUMINUM ALLOYS
}

\author{
Petra WOJNAROVÁ, Jiřina VONTOROVÁ, Jitka MALCHARCZIKOVÁ, Petra VÁŇOVÁ, \\ Karolina SLAMOVÁ
}

VSB - Technical University of Ostrava, Ostrava, Czech Republic, EU, jirina.vontorova@vsb.cz

https://doi.org/10.37904/metal.2020.3607

\begin{abstract}
The article compares the results of three analytical methods for the determination of the chemical composition on the surface of certified standards and aluminum alloy products. It is glow discharge optical emission spectrometry (GDOES), optical emission spectrometry (OES) with spark discharge, and energetic dispersive X-ray fluorescence (ED-XRF). The results are supplemented by oxygen and nitrogen levels determined by thermo-evolutionary elementary analysis. First, standards with a certified composition were measured. It was found that the most appropriate analysis for determining the composition of aluminum alloys (with the exception of the quantitative determination of $\mathrm{Fe}$ and $\mathrm{Zn}$ ) is glow discharge optical emission spectrometry. Optical emission spectrometry with spark discharge was identified as the most appropriate for determining the content of $\mathrm{Fe}$ and $\mathrm{Zn}$. The ED-XRF analysis on the mobile spectrometer is sufficiently accurate in the case of measurement of aluminum alloys, except for magnesium content measurements. It is advantageous to use it mainly where it is not possible to reach a sufficiently large surface of the sample and also where the surface must not be damaged.
\end{abstract}

Keywords: Aluminum alloys, GDOES, ED-XRF, optical emission spectrometry

\section{INTRODUCTION}

The importance of aluminum and its alloys is growing at exponential speed. Aluminum is currently the second most widely used metal and thanks to its excellent combination of physical, chemical and mechanical properties, it can be applied in a number of industries and has become a part of everyday life. According to the latest surveys, overall demand for aluminum is expected to continue to grow. The demand in 2010 is expected to have multiplied 2.3 to 3.5 times by 2050 [1].

The main advantages of aluminum include good thermal and electrical conductivity, high specific thermal capacity and, above all, good hot and cold ductility. The degree of purity and method of processing affects the mechanical properties of aluminum. The main impurities worsening its properties are mainly silicon, iron, oxygen and hydrogen [2]. In an annealed, soft state, aluminum has a tensile strength of $60 \mathrm{MPa}$ and a drawability of $25 \%$. By cold forming, the strength can be significantly increased. In the air, aluminum is quite unstable. On its surface, a layer of $\mathrm{Al}_{2} \mathrm{O}_{3}$ is formed to protect it from further oxidation. It resists weaker acids relatively well but corrodes in contact with alkaline substances [3].

Melted aluminum may contain dissolved gases, metals and a number of compounds, such as nitrides, carbides, sulphides and halides. Only hydrogen is soluble from gases in aluminum, while other gases are inert with it or form insoluble compounds together [4].

The contents of alloying elements used in aluminum alloys vary depending on the specific intended use of the alloy. The most common added elements are [5]: zinc - increases strength, worsens toughness and corrosion 
resistance; magnesium - increases strength and corrosion resistance; manganese - increases strength, malleability and corrosion resistance; silicon - increases the strength of the solid solution (Al-Si alloy is suitable for the production of castings) and slightly increases corrosion resistance; iron - increases ductility and strength, worsens toughness and corrosion resistance; nickel - increases toughness and strength of the alloy; copper - increases strength and hardness, worsens ductility and corrosion resistance.

The biggest consumer of aluminum is the transport industry, which can still be divided into several sub-areas, namely aeronautical [6] and automotive industry, rail transport, ship design and astronautics. For example, the average consumption of aluminum and its alloys in the automotive industry is about $180 \mathrm{~kg}$ per passenger vehicle. Consumption is estimated to increase to $250 \mathrm{~kg}$ in 2050 [7]. The construction industry ranks second in terms of the total consumption of aluminum and its alloys. In the last few decades, its consumption has increased mainly due to the production of industrial facade elements (differently shaped profiles, pipes, windows, roofing, scaffolding, etc.). Recently, aluminum has become a favourite material of some architects, who use it as a building material of large buildings or their components. The aim is to obtain light, airy, corrosion-resistant and stable colour appearance as well as a minimum of maintenance costs [8]. The thirdlargest consumer of aluminum and aluminum alloys is engineering. It participates in the production of a large number of components, machines and equipment. It is used, for example, as part of optical instruments, heat exchangers, pipe components, etc. Aluminum has also been widely used in the food industry, particularly in the production of thin aluminum foils and beverage cans that are easy to recycle [9]. These are an ideal packaging material for storing food, as they are hygienically safe, do not affect the properties of stored food and perfectly tolerate high baking temperatures and, at the same time, low freezing temperatures [10]. At present, aluminum is also significantly used in the production of aluminum foam. This highly porous material with a large surface, low density, high strength and excellent electrical and thermal conductivity can be employed in a number of industrial and other applications [11]. Aluminum is also part of special alloys, e.g. Ti2AIC [12]. Easy-to-weld aluminum alloys are the most suitable material used for 3D printing applications [13].

\section{EXPERIMENTAL MATERIAL}

The correctness and accuracy of the selected methods of chemical composition analysis were verified on certified standards of the ČKD Praha Research Institute, series Al 401 to Al 408.

In addition, real samples were measured, namely one sample of a sports barrier aluminum alloy, one escalator stair sample, and two samples of passenger car wheels of Al-Si-Mg alloy (Figure 1). It was assumed that the composition of these samples would be significantly different.

A

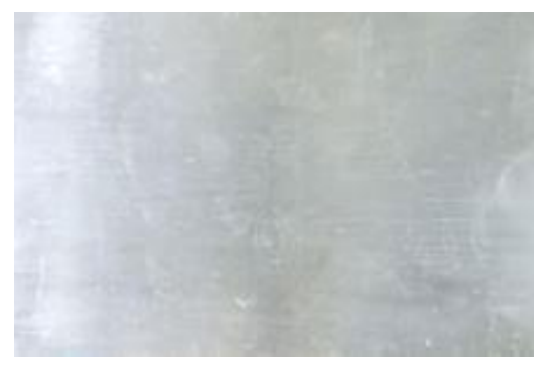

Figure 1 Samples of Al materials: a - sports barrier; $b$ - an escalator stair; $c-1$ st passenger car alloy wheel
C

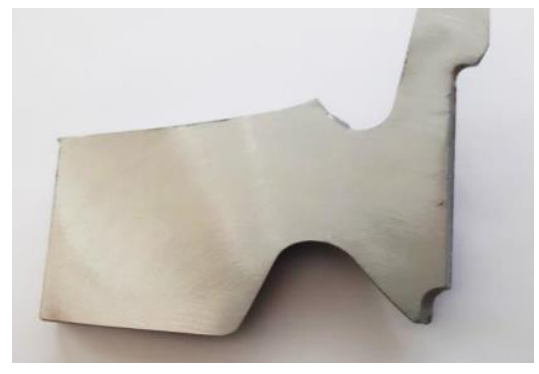

All samples and standards of aluminum alloys had to be thoroughly abraded before the analysis to remove the oxidising surface layer if necessary. At the same time, the surface has been adjusted to make it as flat as possible by grinding. 


\section{EXPERIMENTAL METHODS}

\subsection{Glow discharge optical emission spectroscopy (GDOES)}

In this work, a glow discharge optical emission spectrometer Spectruma Analyst GMBH, model GDA 750 [14, 15] was used. The measurement was carried out at a working temperature of $34.5^{\circ} \mathrm{C}$, a relatively high voltage (approx. $890 \mathrm{~V}$ ) and a very low current (approx. $29 \mathrm{~mA}$ ). As a result of the so-called cathodic dedusting of atoms, a characteristic trace (crater) was formed on the surface of the sample (Figure 2).

\subsection{Optical emission spectrometry with spark discharge (OES)}

An optical emission spectrometer with a spark discharge SPECTROMAXX - Spectro CS, s.r.o. was used for the analysis. The excitation generator used has a semiconductor control, a plasma discharge current between 1 and $80 \mathrm{~A}$, and a discharge duration of $10-10000 \mu \mathrm{s}$. Traces of measurement are shown in Figure 3.

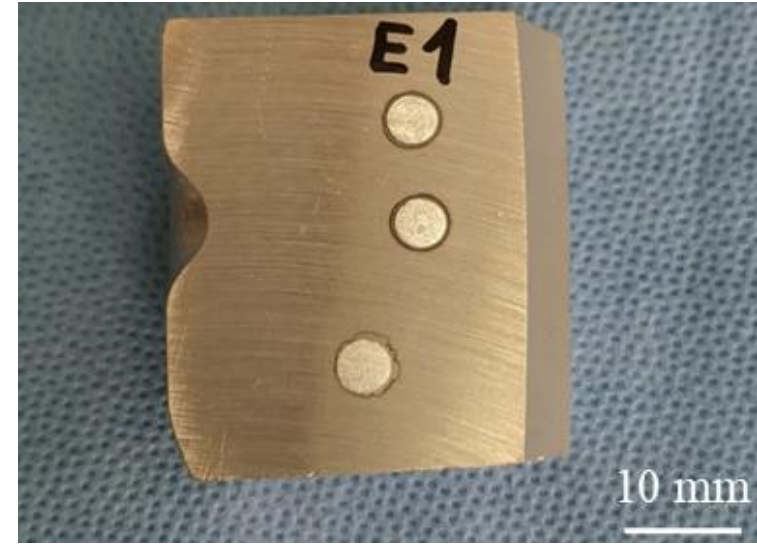

Figure 2 GDOES analysis tracks - 2nd passenger car alloy wheel

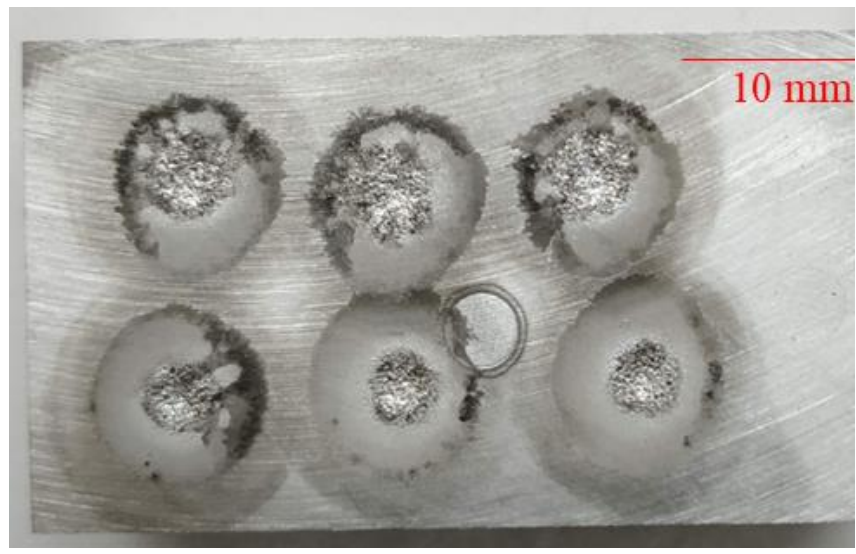

Figure 3 OES spark analysis tracks - Al 401 standard

\subsection{Energy-dispersive X-ray fluorescence (ED-XRF)}

The manual ED-XRF analyser DELTA PROFESSIONAL supplied by the company BAS Rudice s.r.o. was used in the analysis. The device has an X-ray machine with a power of $4 \mathrm{~W}$, and a maximum current of up to $200 \mu \mathrm{A}$ is used to measure light elements. Its main advantages are high speed and relatively good measurement accuracy, as well as a wide range of its use. In addition to the analysis of various metallic materials, it is also used, for example, for the determination of selected elements, including heavy metals in soils. The analysis using this spectrometer does not disturb the surface of the sample.

\subsection{Thermo-evolutionary analysis}

The ELTRA ONH 2000 analyser was used to determine the oxygen and nitrogen content of the alloy samples. Before the analysis, the samples were cut into pieces weighing up to $1 \mathrm{~g}$, and their surface was abraded again to remove the undesirable oxidising layer.

\section{RESULTS AND DISCUSSION}

First, the chemical composition of the standards was measured by all these methods. Then, using correlation charts, the match between certified and measured values was assessed using the least-squares method. For example, Figure 4 shows a correlation chart for the first standard (Al 401). It lists correlation equations and also describes the four elements with the most significant influence. The results of GDOES analyses have the closest slope to one and, therefore, the highest accuracy. These conclusions are also confirmed by the results 
of other standards. OES with spark discharge also provides excellent results. In the case of measuring iron and nickel, it is even more accurate. The third method (ED-XRF analysis) is a rapid non-destructive method. It also gives relatively correct results, with the exception of the determination of magnesium, which was below the limit of detection in all samples.

QC-Expert software was also used for statistical evaluation. The results were compared by paired tests in the module "comparison of two selections". The conclusions were the same - that all elements can be measured by all methods, with the exception of magnesium.

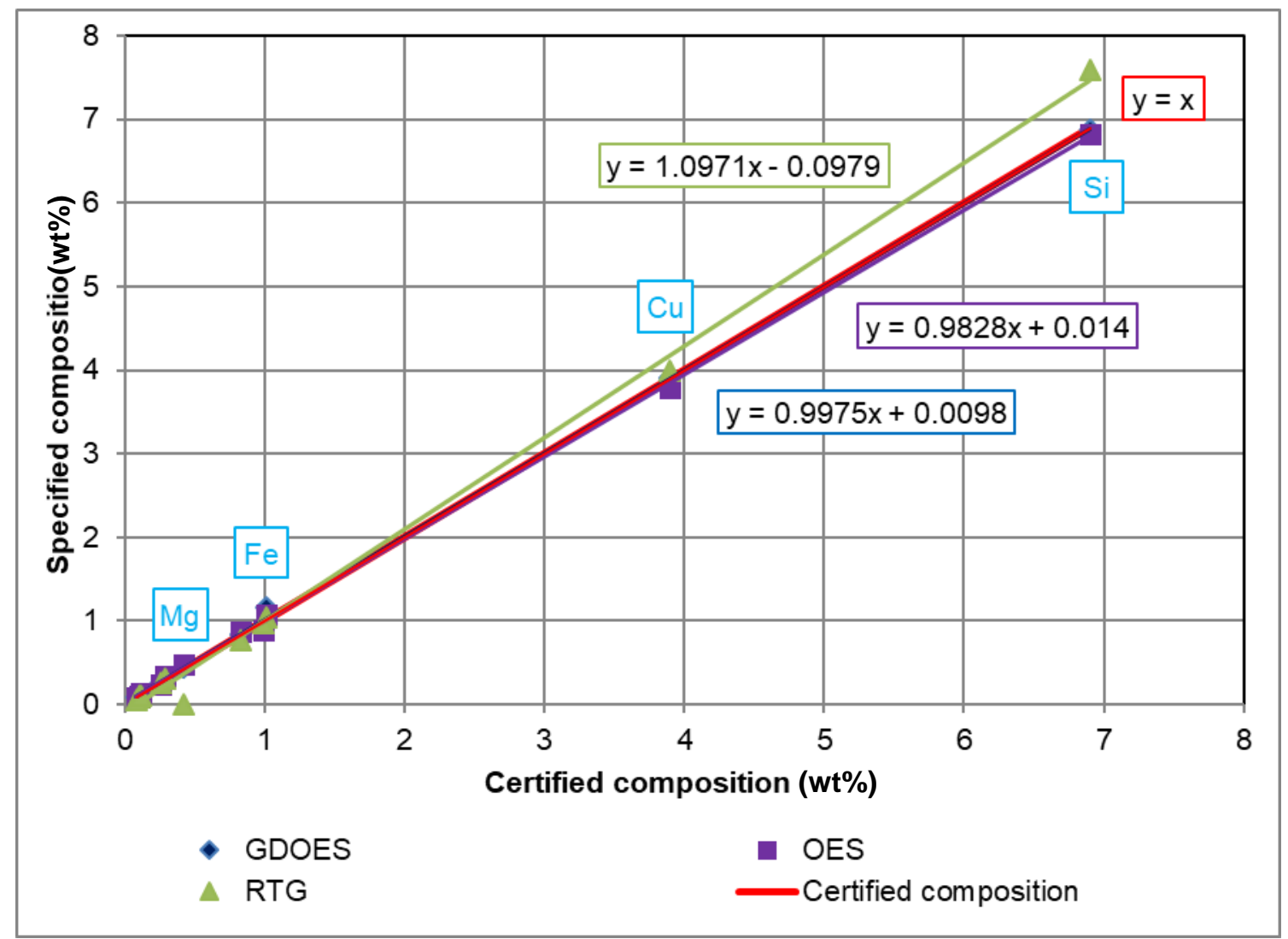

Figure 4 Comparison of results of GDOES, spark OES and ED-XRF analysis with Al 401 certified composition

The chemical composition of all four samples was determined by the spectrometry methods mentioned above. The exception was the measurement of samples of the escalator stair, which could not be analysed by the GDOES method, as the voltage constantly fluctuated during the measurement. The measured mass concentration of the elements in each sample of aluminum alloys is shown in the table below (Table 1). The elements that are not in the table $(\mathrm{Bi}, \mathrm{Co}, \mathrm{Pb}, \mathrm{Sn}$, and $\mathrm{B})$ were measured by all methods below the detection limit. The other elements were subjected to statistical analysis - a pair test of the module "selection comparison" using QC-Expert software. Figure 5 shows the graphical output of this test (for example, the relationship between the results of GDOES and ED-XRF analysis of the sports barrier sample). This is a Bland \& Altman graph in which the $x$-axis is the average of a pair of values, and the $y$-axis is their difference. This graph is used to reveal the possible dependence of variability (expressed by the difference) on the magnitude of the measured value. The confidence interval is marked in red. Statistical analysis showed that in most cases, the results could be measured by all methods. Exceptions are values that have not been included in the average and are marked in red in Table 1. In Table 2, the oxygen and nitrogen contents are added for completeness of analyses. However, these values are negligible. 
Table 1 Chemical composition of samples determined by three methods

\begin{tabular}{|c|c|c|c|c|c|c|c|c|c|}
\hline \multirow{2}{*}{ Sample } & \multirow{2}{*}{ Method } & Si & $\mathrm{Fe}$ & $\mathrm{Cu}$ & $\mathrm{Mn}$ & $\mathrm{Mg}$ & $\mathrm{Ni}$ & Zn & $\mathrm{Ti}$ \\
\hline & & \multicolumn{8}{|c|}{$(w t \%)$} \\
\hline \multirow{4}{*}{$\begin{array}{l}\text { Sports } \\
\text { barrier }\end{array}$} & GDOES & 0.55 & 0.26 & 0.02 & 0.03 & 0.48 & 0.01 & 0.01 & 0.01 \\
\hline & OES & 0.45 & 0.25 & 0.01 & 0.04 & 0.59 & $<0.001$ & 0.01 & 0.02 \\
\hline & ED-XRF & 0.55 & 0.25 & $<0.001$ & 0.04 & 0.36 & $<0.001$ & 0.02 & $<0.001$ \\
\hline & Average & 0.52 & 0.25 & 0.02 & 0.04 & 0.54 & 0.01 & 0.01 & 0.02 \\
\hline \multirow{4}{*}{$\begin{array}{l}\text { Escalator } \\
\text { stair }\end{array}$} & GDOES & & & & 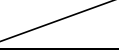 & 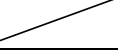 & & & \\
\hline & OES & 12.06 & 0.85 & 0.02 & 0.26 & 0.05 & 0.08 & $<0.001$ & 0.03 \\
\hline & ED-XRF & 11.49 & 0.91 & 0.02 & 0.29 & $<0.001$ & 0.02 & 0.01 & $<0.001$ \\
\hline & Average & 11.78 & 0.88 & 0.02 & 0.28 & 0.05 & 0.05 & 0.01 & 0.03 \\
\hline \multirow{4}{*}{$\begin{array}{c}\text { Alloy wheel } \\
1\end{array}$} & GDOES & 6.35 & $<0.001$ & $<0.001$ & $<0.001$ & 0.25 & $<0.001$ & 0.01 & 0.14 \\
\hline & OES & 5.84 & 0.12 & $<0.001$ & $<0.001$ & 0.24 & $<0.001$ & $<0.001$ & 0.16 \\
\hline & ED-XRF & 7.80 & 0.11 & $<0.001$ & $<0.001$ & $<0.001$ & $<0.001$ & $<0.001$ & 0.10 \\
\hline & Average & 6.66 & 0.12 & $<0.001$ & $<0.001$ & 0.25 & $<0.001$ & 0.01 & 0.13 \\
\hline \multirow{4}{*}{$\begin{array}{c}\text { Alloy wheel } \\
\quad 2\end{array}$} & GDOES & 11.48 & 0.17 & $<0.001$ & $<0.001$ & 0.06 & $<0.001$ & 0.10 & 0.11 \\
\hline & OES & 11.02 & 0.10 & $<0.001$ & 0.01 & 0.10 & $<0.001$ & $<0.001$ & 0.14 \\
\hline & ED-XRF & 12.03 & 0.07 & $<0.001$ & 0.02 & $<0.001$ & $<0.001$ & $<0.001$ & 0.16 \\
\hline & Average & 11.51 & 0.09 & $<0.001$ & 0.02 & 0.08 & $<0.001$ & 0.10 & 0.14 \\
\hline
\end{tabular}

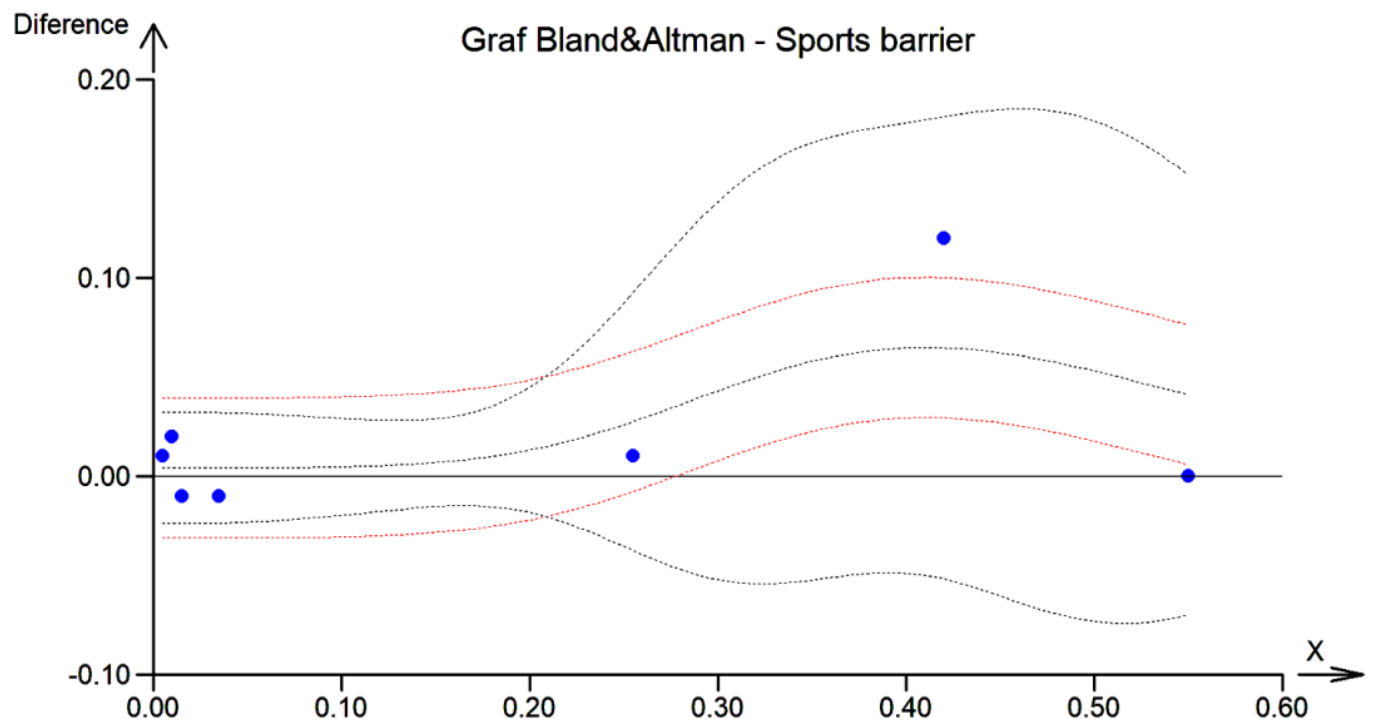

Figure 5 Bland \& Altman chart - comparison of GDOES and ED-XRF sports barrier sample analysis

Table 2 Oxygen and nitrogen content in samples

\begin{tabular}{|c|c|c|c|c|}
\hline $\begin{array}{c}\text { Element } \\
\text { content }\end{array}$ & Sports barrier & Escalator stair & Alloy wheel 1 & Alloy wheel 2 \\
\hline $\mathbf{O}(\mathrm{ppm})$ & $<1$ & $<1$ & $<1$ & $<1$ \\
\hline $\mathbf{N}(\mathrm{ppm})$ & 12 & 16 & 8 & 46 \\
\hline
\end{tabular}




\section{CONCLUSION}

Three methods (GDOES, spark OES and ED-XRF) measured the chemical composition of eight standards and four samples with different chemical composition. For complete knowledge of the chemical composition of the samples, the results were supplemented with oxygen and nitrogen content using elementary thermoevolution analysis. In the samples studied, the contents of these elements were negligible.

The measurement of $\mathrm{Al} 401$ to $\mathrm{Al} 408$ standards verified the correctness of the results of these methods. The results have shown that the most appropriate method for determining the composition of aluminum alloys is GDOES. However, this method has the highest demands on the quality of the monitored surface. The surface must be flat, non-porous, and the shape of the sample must not be too irregular (as in the case of escalator stairs). Optical spark discharge emission spectrometry can be recommended as an alternative method for determining the content of alloying elements (and, at the same time, the best method for determining iron and nickel). ED-XRF X-ray analysis on the mobile spectrometer is high-speed and sufficient for a wide range of applications and indicative composition determination. In the case of measurement of aluminum alloys, it is not suitable for magnesium measurement. It is convenient to use it mainly if it is not possible to reach a sufficiently large surface of the sample and also if the surface must not be damaged.

\section{ACKNOWLEDGEMENTS}

This work was supported by VŠB-Technical University of Ostrava: SP2020/39, SP2020/44 and SP2020/14. The work was supported from ERDF "Institute of Environmental Technology - Excellent Research "(No. CZ.02.1.01/0.0/0.0/16_019/0000853). Experimental results were accomplished by using Large Research Infrastructure ENREGAT supported by the Ministry of Education, Youth and Sports of the Czech Republic under project No. LM2018098.

\section{REFERENCES}

[1] ELSHKAKI, A., LEI, S., CHEN, W.-Q. Material-energy-water nexus: Modelling the long term implications of aluminum demand and supply on global climate change up to 2050. Environmental Research. 2020, vol. 181.

[2] ASHKENAZI, D. How aluminum changed the world: A metallurgical revolution through technological and cultural perspectives. Technological Forecasting and Social Change. 2019, vol. 143, pp. 101-113.

[3] KOK, M. Production and mechanical properties of $\mathrm{Al}_{2} \mathrm{O}_{3}$ particle - reinforced 2024 aluminum alloy composites. Journal of materials Processing Technology. 2005, vol. 161, pp. 381-387.

[4] HAN, Y., XUE, S., FU, R., LIN, L., LIN, Z., PEI, Y., SUN, H. Influence of hydrogen embrittlement on impact property and microstructural characteristics in aluminum alloy weld. Vacuum. 2020, vol. 172.

[5] HATCH, J. E. Aluminum: properties and physical metallurgy. Metal Park, OH: American Society for Metals, 1984.

[6] STARKE, E.A, STALEY, J.T. Application of modern aluminum alloys to aircraft. Progress in Aerospace Sciences. 1996, vol. 32, iss. 2-3, pp. 131-172.

[7] SANTOS, M. C., MACHADO, A. R., SALES, W. F., BARROZO, M. A. S., EZUGWU, E. O. Machining of aluminum alloys: a review. International Journal of Advanced Manufacturing Technology. 2016. vol. 86, iss. 9-12, pp. 30673080 .

[8] LI, Y., YUE, Q., HE, J., ZHAO, F., WANG, H. When will the arrival of China's secondary aluminum era? Resources Policy. 2020, vol. 65.

[9] BROŽOVÁ, S., PUSTĚJOVSKÁ, P., INGALDI, M. Economic and technological aspects of the use of secondary metal-bearing raw materials for metallurgical production. In Metal 2014: 23rd International conference on metallurgy and materials. Conference proceedings. Brno, 2014, pp. 1618-1622.

[10] MICHNA, Š., KUŚMIERCZAK S. Technology and processing of aluminum materials. (syllabus). Ústí nad Labem: Fakulty of Mechanical Engineering, Jan Evangelista Purkyně University. 2008. (in Czech). 
[11] KUMAR, R., JAIN, H., SRIRAM, S., CHAUDHARY, A., KHARE, A., Ch, V. A. N., MONDAL, D. P. Lightweight open cell aluminum foam for superior mechanical and electromagnetic interference shielding properties. Materials Chemistry and Physics. 2020, vol. 240.

[12] ČEGAN, T., CAGALA, M., KURSA, M, KAWULOK, P., RUSZ S., JUŘICA, J., VONTOROVÁ, J. Effect of Ti2AIC particles on the microstructure and elevated-temperature-deformation properties of gamma-TiAl Alloys. Materiali in tehnologije. 2014, vol. 48, iss. 6, pp. 831-835.

[13] CANTER, N. Manufacturing of aluminum alloys by 3D printing. Tribology and Lubrication Technology. 2018, vol. 74, iss. 1, pp. 12-13.

[14] VONTOROVÁ, J., MOHYLA, P. Use of GDOES method for evaluation of the quality and thickness of hot dip galvanised coating. Transactions of the Institute of Metal Finishing. 2018, vol. 96, no. 6, pp. 313-318.

[15] VONTOROVÁ, J., VÁŇOVÁ, P. Determination of carburized layer thickness by GDOES method, AIMS Materials Science. 2018, vol. 5, no. 1, pp. 34-43. 